\title{
Research on Vertical Bearing Capacity of Ram-compacted Pile with Vibrating Gravel Base in Collapsible Loess Foundation
}

\author{
Yifan Yang ${ }^{1, \text { a) }}$, Lin Zhu ${ }^{*}$, $)$, Haoyu Ma ${ }^{2, c)}$ \\ ${ }^{1,2}$ College of Architecture and Civil Engineering, Beijing University of Technology, Beijing 100124, China. \\ ${ }^{*}$ College of Architecture and Urban Planning, Beijing University of Technology, Beijing 100124, China. \\ a)yang_yifan@hotmail.com \\ b)judy_12@163.com \\ c)mhyjob@foxmail.com
}

\begin{abstract}
Ram-compacted piles with vibrating gravel base is a simple method of foundation treatment which was applied to engineering in soft soil areas initially with which soil surrounding can be compacted by the impact of hammer transitted by gravel. Relatively low cost and ordinary construction technique have made it begin to take shape in general industrial and civil engineering. However, a mature frame of reference about the application of ram-compacted piles with vibrating gravel base in collapsible loess foundation especially vertical bearing capacity is still under research. This paper proposes a theoretical hypothesis of pile-soil model based on Mohr-Coulomb Model. The results of finite element analysis of ram-compacted piles with vibrating gravel base are used to verify that its vertical bearing capacity is up to standard generally while stress concentration on the uneven boundary of concrete and gravel base can not be ignored as well.
\end{abstract}

Keywords. Ram-compacted Pile, Pile-soil Analysis, Foundation Treatment

\section{INTRODUCTION}

How to ensure both reliability and economical efficiency of the treatment of collapsible loess foundation remains a highly debatable issue among many. In some relatively underdeveloped areas, Cement Fly-ash Gravel (CFG) is a popular method because of its simple operation and in-expensive construction materials. However, CFG has two inherent defects. Firstly, CFG is a kind of flexible pile group foundation whose capability of resisting horizontal shear is considerably weak at the expense of cost. It was proved to be susceptible to slip circle shear failure by Jiang [1] with FLAC3D (Fast Lagrangian Analysis of Continua, 3 dimensions) software. Secondly, stress concentration of pile end soil caused by lowly integral stiffness will result in the decline of bearing capacity of foundation. A threedimensional nonlinear finite element analysis of Zheng [2] indicated that the thickness of cushion plays a more significant role than pile net itself in the load distribution between piles and subsoil. Under this background, an innovative construction technique named ram-compacted piles with vibrating gravel base was invented in soft clay areas which can effectively reinforce foundation of industrial and civil architecture, even that of railway engineering. According to the statistics of field tests conducted by Ma [3], ram-compacted piles with vibrating gravel base is capable to reduce settlement of roadbed in soft soil areas efficiently. What is more, a series of research by Chen [4] indicated that the improvement of properties of adjacent soil surrounding piles can increase ultimate bearing capacity of foundation apparently. Currently, ram-compacted piles with vibrating gravel base is on trial in Ningxia Hui Autonomous Region of P.R.China where collapsible loess is widely distributed. The sketch of ram-compacted pile with vibrating gravel base is shown in Fig. 1. With the reinforcement brought by the impact of hammer, gravel 
and compresses soil can reduce the stress concentration effectively in a limited budget. Besides, standard concrete after uniform mixing can provide a stronger shear-bearing capacity than CFG.
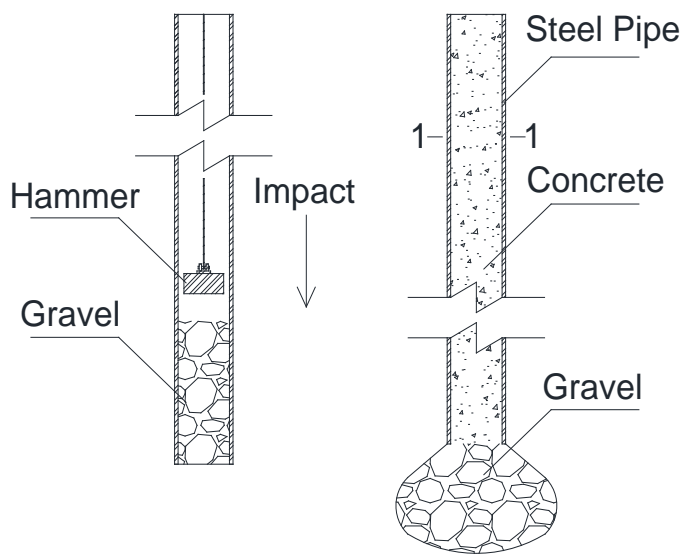

1-1

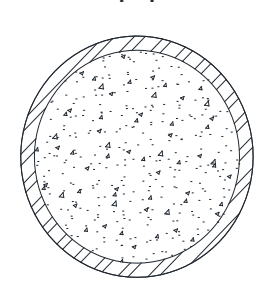

FIGURE 1. Sketch of ram-compacted pile

\section{PHYSICAL MECHANISMS OF COLLAPSIBLE LOESS FOUNDATION \\ Compressive Properties}

Loess of Upper Pleistocene $\left(\mathrm{Q}_{3}\right)$ and that of Holocene $\left(\mathrm{Q}_{4}\right)$ are the soil layers directly related to the construction of ordinary architectures. Many studies have been performed to understand the compressive properties of collapsible loess. Chen [5] conducted consolidateded drained triaxial tests on collapsible loess, and the compression curves are shown in Fig. 2. 

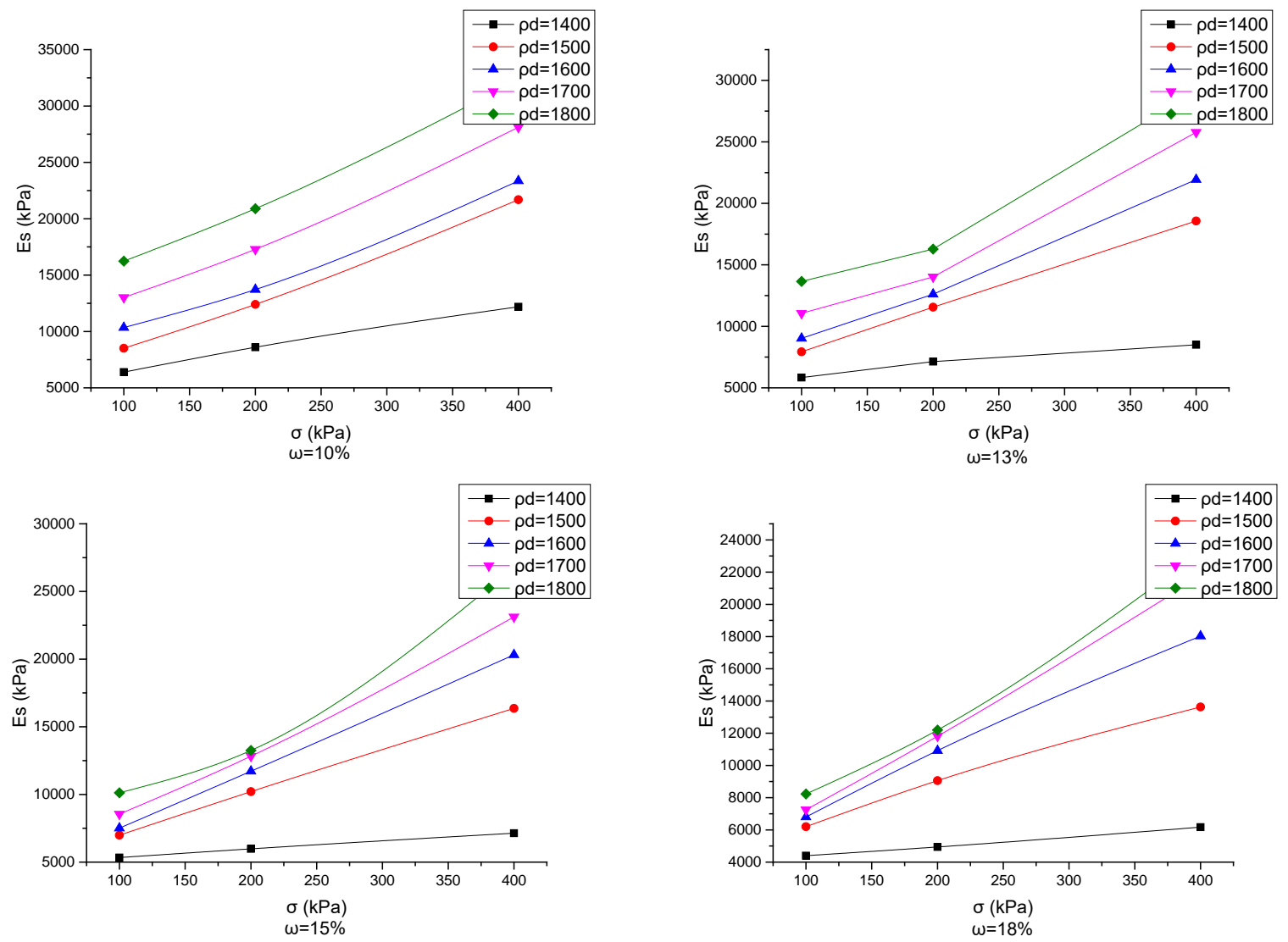

FIGURE 2. Relationship between compressive modulus and vertical pressure

\section{Shear Properties}

From the perspective of Fang [6], collapsible loess has large porosity and developed joint, the failure form is limited by $\sigma_{3}$, the confining pressure. When $\sigma_{3}<p_{s}$, the stress-strain curves indicates that loess faces softening failure brittlely. When $\sigma_{3}>p_{\mathrm{s}}$, the loess faces plastic reinforcement. When $\sigma_{3}=p_{\mathrm{s}}$, the soil mass is in a limit condition. The $\tau-\varepsilon$ curves of upper loess are shown in Fig. 3. 


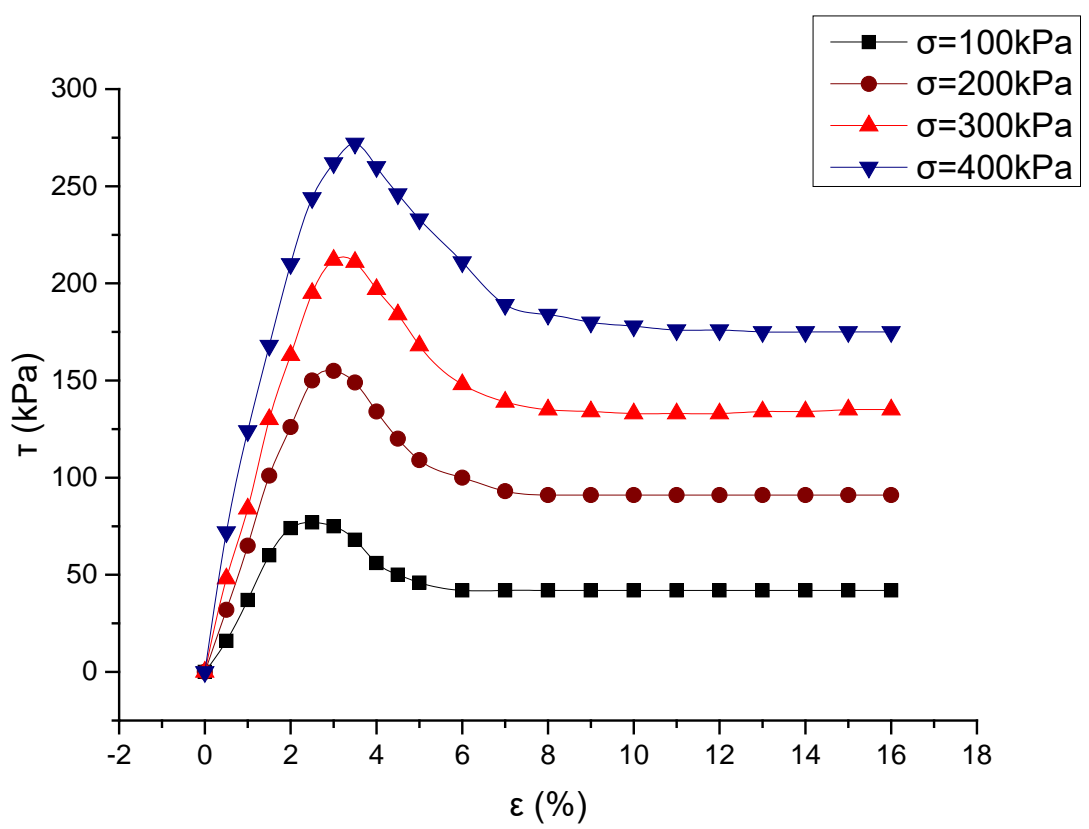

FIGURE 3. Relationship between normal strain and shear stress of upper loess

To be general, with the increase of normal stress, modulus of compression rises up. As a result, there should be a positive correlation between normal stress and Young's modulus of loess within a certain range. What is more, in triaxial stress state, there is an approximately linear relationship between normal strain and shear stress of loess before its reaching the limit condition after which the curves are distributed nonlinearly, indicating that elastic theory is not applicable in this work.

\section{Mechanism Analysis of Side Friction of Surrounding Soil}

According to the theory of Poulos [7-8], the ratio of the stiffness of pile and surrounding soil is the main factor affecting load transfer. As a result, effective stress and internal friction angle of soil play important roles in this occasion. Since ram-compacted piles are designed to be applied in shallow soil layers, extra stress in different depth of soil without human disturbance can be regarded as the same. As a result, the calculation of ultimate side friction can be described by the following equation:

$$
\tau_{\mathrm{u}}=\mathrm{c}_{\mathrm{a}}+\sigma_{\mathrm{x}} \tan \varphi_{\mathrm{a}}
$$

where $\mathrm{c}_{\mathrm{a}}$ and $\varphi_{\mathrm{a}}$ are cohesion yield stress and friction angle between the pile and surrounding soil respectively, $\sigma_{\mathrm{x}}$ is the normal pressure of the surface of pile whose depth is $z . \sigma_{x}$ is in direct proportion to vertical effective stress of surrounding soil, one obtains:

$$
\tau_{\mathrm{u}}=\mathrm{C}_{\mathrm{a}}+\mathrm{K}_{\mathrm{s}} \sigma_{\mathrm{v}} \tan \varphi_{\mathrm{a}}
$$

where $\sigma_{\mathrm{v}}^{\prime}$ is the vertical effective stress of surrounding soil, $\mathrm{K}_{\mathrm{s}}$ is a positive constant.

According to eq. (2), side friction of surrounding soil is distributed nonlinearly because of the differences among layers. It depends on vertical effective stress, cohesion yield stress and friction angle.

\section{ANALYSIS OF PILE-SOIL SYSTEM}

\section{Engineering Hypothesis and Pile-soil Model}

This work was analyzed by ABAQUS 6.13. Firstly, the model was divided into six parts. The section plan of the soil-pile model is shown in Fig. 4. 


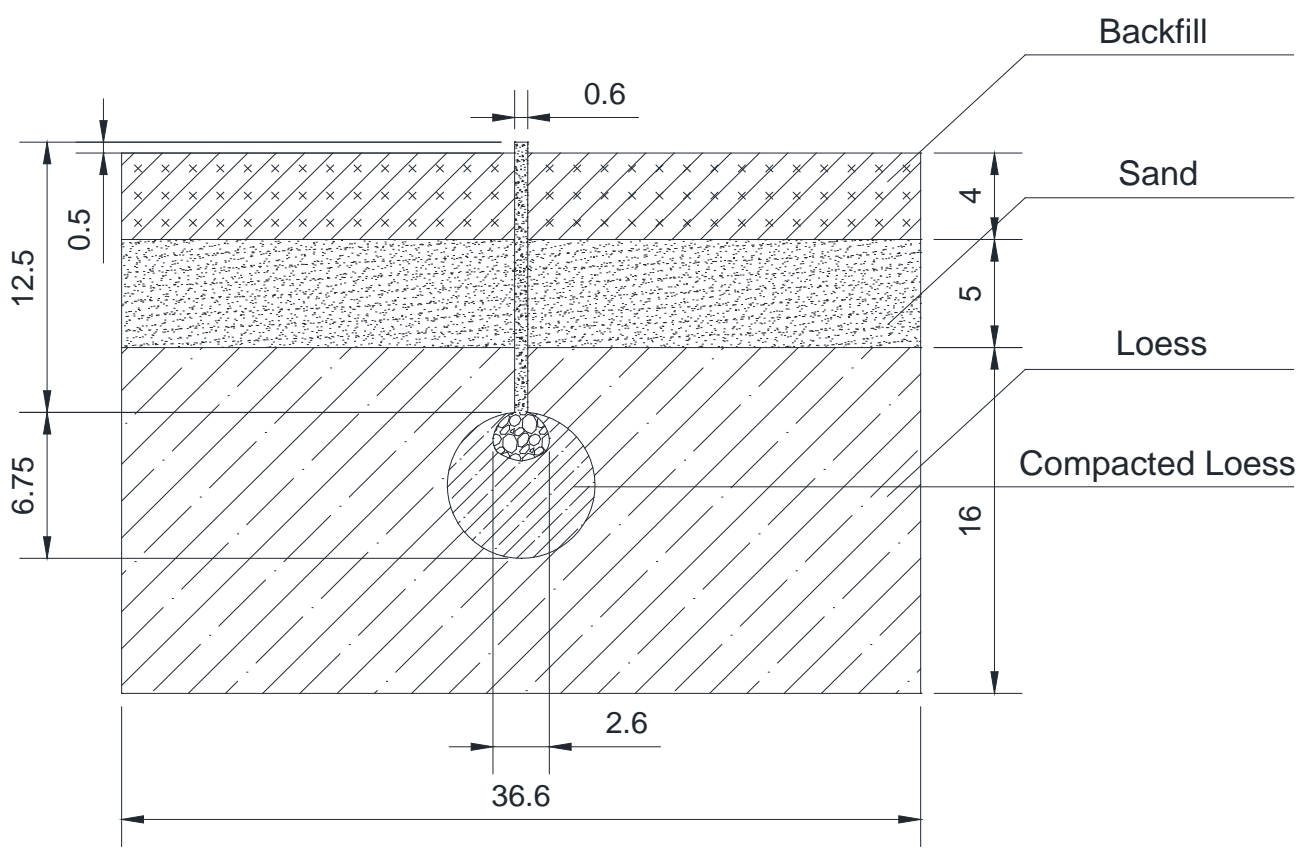

FIGURE 4. Section plan of pile-soil model

As shown in Fig. 4, the pile is made of concrete, the base is made of gravel filled with cement-sand mortar, layer-1 is made of backfill, layer-2 is made of sandy soil, layer-3 is made of loess, layer-4 is made of compacted loess. From the perspective of Massoudi [9] and Wu [10], in uniaxial load state of granular material, Mohr-Coulomb theory is practical for finite element analysis. Referring to theoretical analysis in Section 2, properties of different parts are defined as shown in Table 1.

TABLE 1. Properties of different parts (SI)

\begin{tabular}{ccccccc}
\hline Part & Density & Young's Modulus & Poison's Ratio & Friction Angle & Dilation Angle & Cohesion Yield Stress \\
\hline Pile & 2400 & $2.8 \mathrm{E} 10$ & 0.20 & - & - & - \\
Base & 2500 & $2.2 \mathrm{E} 10$ & 0.18 & - & - & - \\
Layer-1 & 1800 & 1E8 & 0.30 & $23^{\circ}$ & $2^{\circ}$ & 75000 \\
Layer-2 & 1650 & $1 \mathrm{E} 8$ & 0.35 & $20^{\circ}$ & $2^{\circ}$ & 60000 \\
Layer-3 & 1850 & $1 \mathrm{E} 8$ & 0.30 & $25^{\circ}$ & $2^{\circ}$ & 80000 \\
Layer-4 & 2100 & $1.4 \mathrm{E} 8$ & 0.25 & $38^{\circ}$ & $2^{\circ}$ & 120000 \\
\hline
\end{tabular}

\section{Operating Mode-1}

In this mode, the pile worked with the absence of vibrating gravel base while the length of the pile is $12 \mathrm{~m}$. Thickness of different layers and properties of different materials are same with those given in Fig. 4 and Table 1. The S22 nephogram is shown in Fig. 5. 


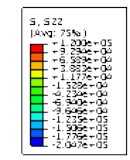

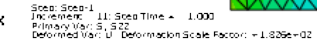

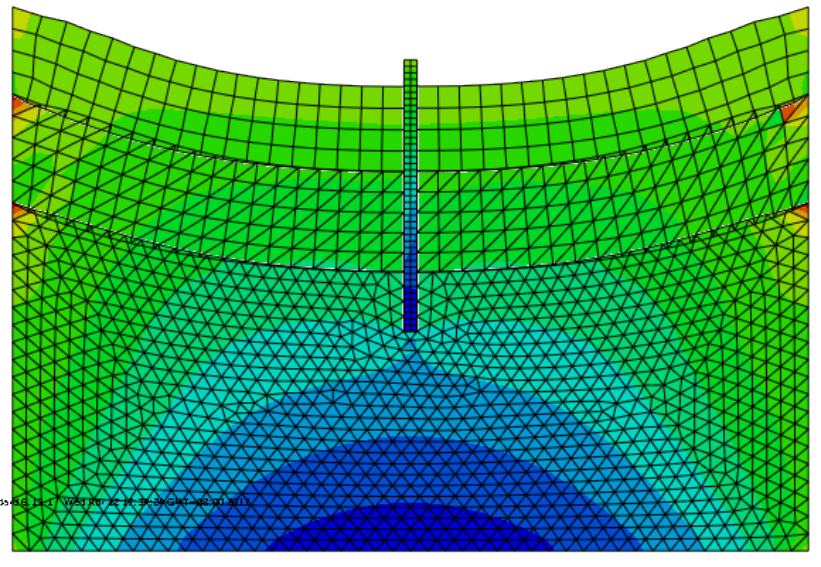

FIGURE 5. S22 nephogram of operating mode-1

As shown in the figure, there is stress concentration in pile end soil whose sphere of influence is about three times as the diameter of the pile. Statistics of settlement are sorted in Section 3.

\section{Operating Mode-2}

In this mode, the pile worked with vibrating gravel base while the length of the pile is $12 \mathrm{~m}$. The S22 nephogram is shown in Fig. 6.

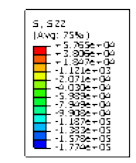

FIGURE 6. S22 nephogram of operating mode-2

Condition of load transfer improves apparently in this mode. According to Deng [11] and Shahin [12], constraint of loess and compacted loess can be considered as nonlinear equivalent concentrated springs of different stiffness coefficient. With the expansion of bearing area, stress concentration reduces apparently. However, there is stress concentration on the uneven boundary of concrete and gravel base which might result in the development of vertical crack, weakening horizontal bearing capacity of this pile. Mises nephogram of operating mode-2 is shown in Fig. 7. 

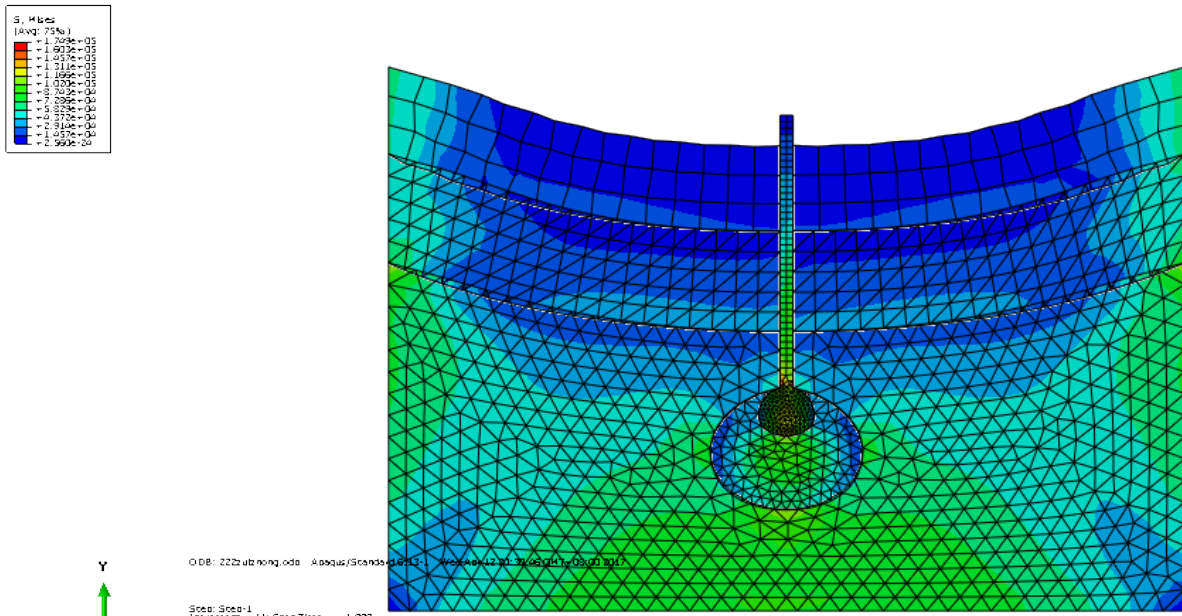

FIGURE 7. Mises nephogram of operating mode-2

\section{SETTLEMENT CALCULATION}

\section{Time-settlement Curves}

The curves are shown in Fig. 8. With different load, there is an apparent linear relationship between these two factors in initial settlement period.
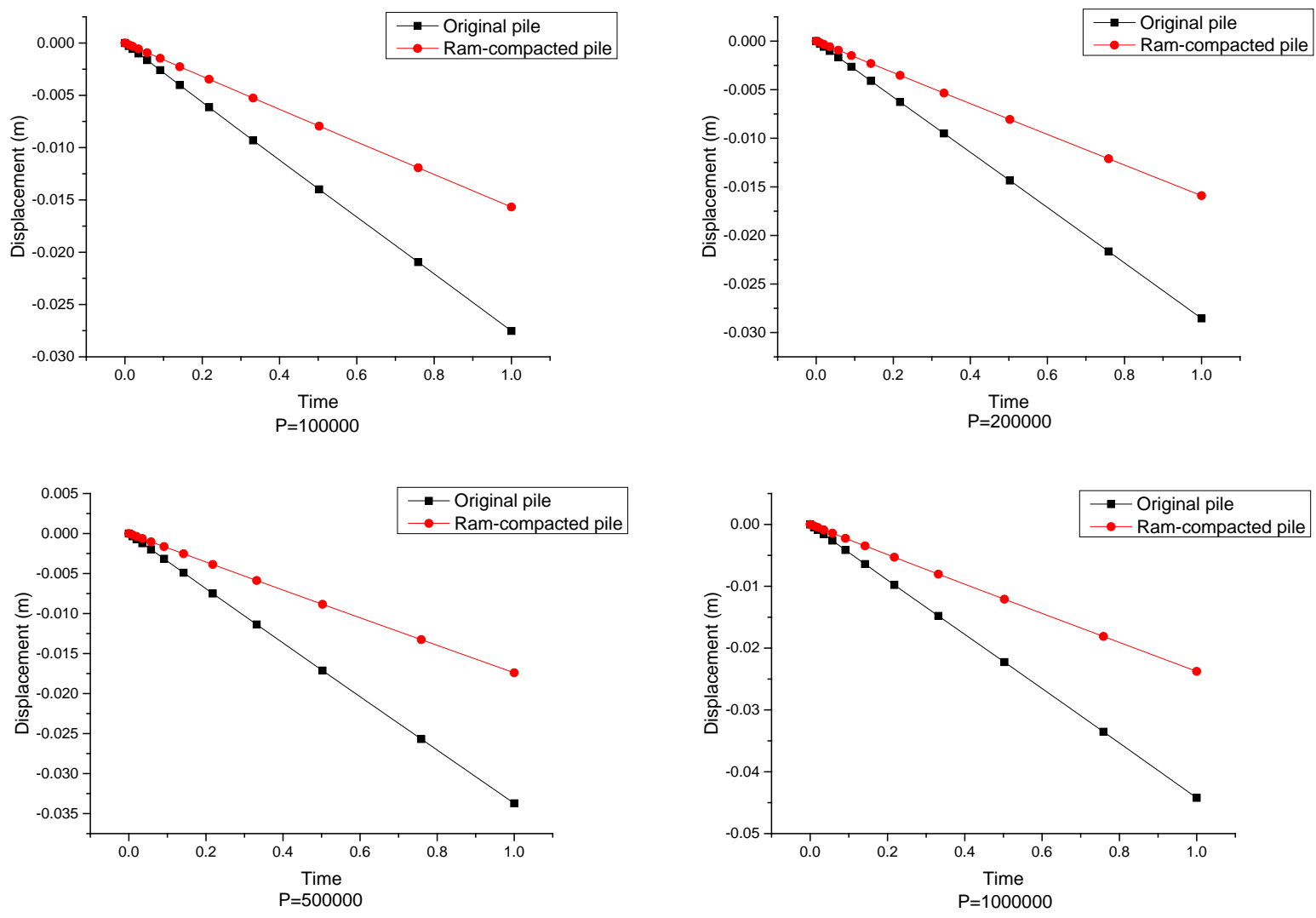

FIGURE 8. Relationship between time and settlement of operating mode- 1 and operating mode-2 
Obviously, ram-compacted pile's rate of settlement is much lower than that of original pile while its final settlement is much less than that of origin pile as well.

\section{Load-settlement Curves}

The curves are shown in Fig. 9. With the same load, settlement of original pile is approximately twice as much as that of ram-compacted pile. However, the curve of ram-compacted pile is smoother than expected. It drops a little more dramatically when the load is about $700 \mathrm{kPa}$.

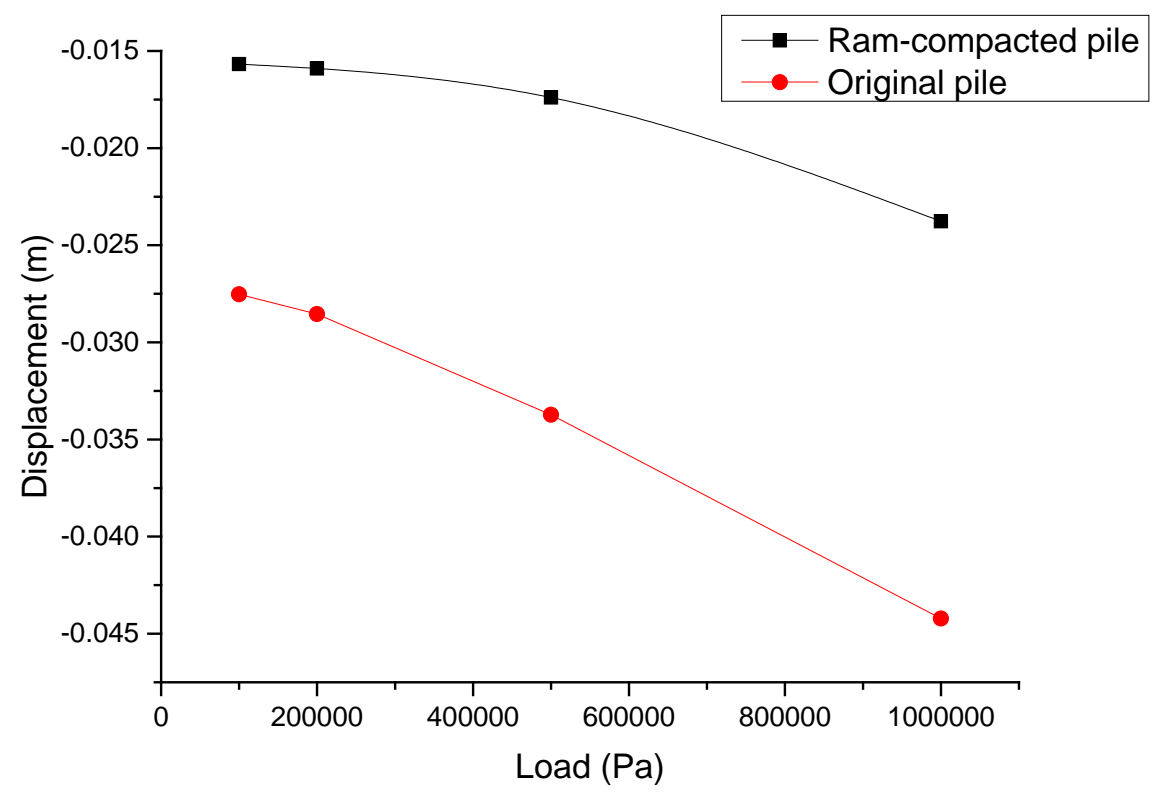

FIGURE 9. Relationship between load and settlement of operating mode-1 and operating mode-2

\section{CONCLUSION}

The following conclusions may be drawn from this study:

A series of finite element analysis indicated that the vertical bearing capacity of ram-compacted piles with vibrating gravel base in collapsible loess foundation is much better than that of piles without vibrating gravel base with the absence of precipitation. The base made of vibrating gravel reduces stress concentration effectively (sphere of influence of subsidiary stress increased from $2 \mathrm{~m}$ to $7 \mathrm{~m}$ approximately). Besides, engineering property of collapsible loess beneath the bottom of piles improved dramatically after the ram which resulted in the increase of vertical bearing capacity. To be more specific, with the absence of ram and vibrating gravel base, the settlement of foundation treated by ram-compacted pile with vibrating gravel base is about $0.019 \mathrm{~m}$ if the vertical load of a single pile (whose acreage is $0.28 \mathrm{~mm} 2$ ) is $500 \mathrm{kPa}$. However, that of ram-compacted piles without vibrating gravel base is $0.037 \mathrm{~m}$ under the same circumstances described in Section 2.

However, there remains a hidden risk that stress concentration exists obviously at the interface between concrete pile and gravel base because of the unevenness of gravel which improves the development of vertical crack of concrete pile, weakening the coupling of pile and base, even influencing anti-seismic capability of the whole building structure.

\section{ACKNOWLEDGMENTS}

The first author of this paper is Yifan Yang, the corresponding author is Lin Zhu. This work was financially supported by Beijing University of Technology. Besides, the authors would like to thank Institute of Economic and Technology of State Grid Ningxia Electric Power Company and Ningxia Institute of Architectural Design Co., Ltd. 


\section{REFERENCES}

1. Jiang, D. and B. Wang. An analysis on failure pattern of CFG pile-net composite foundation of high-speed railway. in 2012 Global Conference on Civil, Structural and Environmental Engineering, GCCSEE 2012 and the 3rd International Symposium on Multi-field Coupling Theory of Rock and Soil Media and Its Applications, MCTRSM 2012, October 20, 2012 - October 21, 2012. 2012. Yichang, China: Trans Tech Publications.

2. Zheng, J., S.W. Abusharar and X. Wang, Three-dimensional nonlinear finite element modeling of composite foundation formed by CFG-lime piles. Computers and Geotechnics, 2008. 35(4): p. 637-643.

3. Ma, J., et al. The field test for influence of ram-compacted piles with bearing base on settlement of embankments in China Beijing-Shanghai high-speed railway on deep soft soil. in 15th Asian Regional Conference on Soil Mechanics and Geotechnical Engineering, ARC 2015, November 9, 2015 - November 13, 2015. 2015. Fukuoka, Kyushu, Japan: Asian Regional Conference on Soil Mechanics and Geotechnical Engineering.

4. Chen, Y.H., et al. Experimental study on soft ground improvement by grouted gravel pile. in 2009 GeoHunan International Conference - Recent Advancement in Soil Behavior, In Situ Test Methods, Pile Foundations, and Tunneling, August 3, 2009 - August 6, 2009. 2009. Changsha, Hunan, China: American Society of Civil Engineers (ASCE).

5. Fang, Q., et al., Experimental research on elastic resistant coefficient, deformation and compressive moduli of surrounding rock in large-section loess tunnel. Yanshilixue Yu Gongcheng Xuebao/Chinese Journal of Rock Mechanics and Engineering, 2009. 28(SUPPL. 2): p. 3932-3937.

6. Chen, K. and A. Sha, Study of deformation characteristic of compacted loess. Yantu Lixue/Rock and Soil Mechanics, 2010. 31(4): p. 1023-1029.

7. Poulos, H.G. and N.S. Mattes, Behaviour of axially loaded end- bearing piles. 1969. 19(2): p. 285-300.

8. Poulos, H.G. Pile testing and settlement prediction. in GeoCongress 2012 - Full-Scale Testing and Foundation Design: Honoring Bengt H. Fellenius, March 25, 2012 - March 29, 2012. 2012. Oakland, CA, United states: American Society of Civil Engineers (ASCE).

9. Massoudi, M. and M.M. Mehrabadi, A continuum model for granular materials: Considering dilatancy and the Mohr-Coulomb criterion. Acta Mechanica, 2001. 152(1-4): p. 121-138.

10. Wu, W.T., et al., Normal stress effects in the gravity driven flow of granular materials. International Journal of Non-Linear Mechanics, 2017. 92: p. 84-91.

11. Deng, H., X. Xie and Y. Guo, Study on load transfer and determination method of bearing capacity for enlarged pile. Yanshilixue Yu Gongcheng Xuebao/Chinese Journal of Rock Mechanics and Engineering, 2005. 24(SUPPL.): p. 4934-4940.

12. Shahin, M.A. Artificial intelligence for modeling load-settlement response of axially loaded bored piles. in 8th European Conference on Numerical Methods in Geotechnical Engineering, NUMGE 2014, June 18, 2014 June 20, 2014. 2014. Delft, Netherlands: Taylor and Francis - Balkema. 